\title{
The Dry Salvages ${ }^{1}$
}

\author{
T. S. Eliot
}

(trad. de Isabel Pérez Montfort, José

Martín Díaz y Gabriel Astey)

\section{I}

Yo no sé mucho de dioses, pero creo que el río

es un fuerte dios marrón - hosco, bravo, intratable,

paciente hasta cierto punto, al principio visto como frontera;

útil, traicionero como transportador del comercio;

después, solo un problema para el constructor de puentes.

Resuelto el problema, el dios marrón es casi olvidado

por los que viven en ciudades; pese a todo, siempre es implacable.

Con sus épocas y rabias, destructor, recuerda

a los hombres lo que eligen olvidar.

Sin honra, sin plegarias de los adoradores

de la máquina, permanece a la espera, vigilante y a la espera.

$\mathrm{Su}$ ritmo estaba en el cuarto de los niños, en el frondoso ailanto del jardín en abril, en el olor de las uvas sobre la mesa otoñal, y en la aureola nocturna del candil en invierno.

Llevamos el río por dentro, el mar entero nos rodea;

el mar es también el borde de la tierra, las rocas

a las que llega, las playas donde arroja

los vestigios de una creación diferente y anterior:

la estrella de mar, el cangrejo, el espinazo de la ballena;

las pozas donde ofrece a nuestra curiosidad

las algas más delicadas y la anémona.

Arroja nuestras pérdidas, las redes desgarradas,

la nasa hecha pedazos, el remo quebrado

${ }^{1}$ The Dry Salvages — supuestamente les trois sauvages - es un pequeño roquedal, con un faro, en la costa noreste de Cape Ann, Massachusetts. Salvages se pronuncia de modo que rime con assuages (nota del autor). 
y los pertrechos de extranjeros muertos. El mar tiene muchas voces, muchos dioses y muchas voces.

La sal está en la rosa silvestre, la niebla en los abetos.

El rugido del mar, y su lamento son voces diferentes que suelen oírse juntas; la queja en los cordajes, la amenaza y la caricia de olas que rompen mar adentro, el silbido distante de la espuma en los dientes de la roca y el aviso suplicante desde el risco que se acerca son todas voces del mar, y el resuello de la boya que llama hacia la tierra, y la gaviota: y bajo el peso de la niebla silenciosa la campana que tañe mide un tiempo, que no es nuestro, hecha sonar por la marea parsimoniosa, un tiempo más antiguo que el de los cronómetros, más antiguo que el tiempo que cuentan ansiosas mujeres preocupadas que yacen despiertas calculando el futuro, tratando de destejer, desenredar, desenmarañar y articular el pasado y el futuro, entre la medianoche y la alborada, cuando el pasado es todo engaño, y en el futuro no hay futuro, antes de la ronda matinal, cuando el tiempo se detiene y nunca acaba, y la marea, que es y fue desde el principio, tañe la campana. 


\section{II}

¿Dónde acaba esto, el lamento callado, el marchitarse silencioso de las flores de otoño que sueltan sus pétalos y permanecen inmóviles? ¿Dónde acaban los restos sin rumbo del naufragio, la plegaria del hueso en la arena, la inefable plegaria en la anunciación desastrosa?

No hay final, sino suma: la consecuencia extendida de otros días y horas, mientras la emoción se lleva consigo los años sin emoción, vividos entre los destrozos de lo que se creía más confiable $-\mathrm{y}$, por tanto, era más digno de renuncia.

Existe la suma final, el orgullo frustrado o el resentimiento ante las facultades disminuidas, el amor sin apego, que podría parecer desamor, en un bote a la deriva con una fuga lenta, la escucha silenciosa del innegable clamor de la campana de la última anunciación.

¿Dónde acaban ellos, los pescadores que navegan hacia la cola del viento, donde la niebla se acobarda? No se puede pensar en un tiempo sin océano ni en un océano limpio de despojos ni en un futuro incapaz, como el pasado, de no tener destino.

Hay que imaginarlos siempre achicando, haciéndose a la mar e izando velas, mientras el viento del noreste desciende sobre bancos poco profundos, inmutables y sin erosión; o cobrando su jornal, secando velas en los muelles; no emprendiendo un viaje que sería incosteable por una pesca que no valdría la pena. 
Esto no tiene fin: el lamento sin voz, no tiene fin el marchitarse de las flores marchitas, el movimiento del dolor que no duele ni se mueve, la deriva del mar y los despojos a la deriva, la plegaria del hueso a la muerte, su dios. Solo la difícil y apenas pronunciable plegaria de la única Anunciación.

Conforme uno se hace viejo, parece que el pasado toma otra forma, y deja de ser una simple secuencia -o incluso un desarrollo: esto es una falacia parcial, alentada por nociones superficiales de evolución, que se vuelve, en la idea de la gente, una manera de negar el pasado. Los momentos de felicidad — no la sensación de bienestar, gozo, satisfacción, seguridad y afecto, o incluso una muy buena cena, sino la iluminación repentinatuvimos esa experiencia pero perdimos el significado, y acercarse al significado restaura la experiencia de forma diferente, más allá de cualquier significado que le podamos dar a la felicidad. Dije antes

que la experiencia pasada que resurge en el significado no es la experiencia de una sola vida sino de muchas generaciones — sin olvidar algo que es quizá inefable:

la mirada hacia atrás más allá de la seguridad de la historia escrita, el vistazo hacia atrás por encima del hombro hacia el terror primitivo. Así descubrimos que los momentos de agonía (se deban o no a malentendidos; haberse equivocado en la esperanza o el temor, esa no es la cuestión) también son permanentes, con esa permanencia que el tiempo tiene. Vemos esto mejor en la agonía de los otros, que se vive de cerca y nos involucra, que en la nuestra.

Pues nuestro pasado está cubierto por las corrientes de la acción, 
pero el dolor de los otros es siempre una experiencia inalterada, invulnerable al desgaste posterior.

La gente cambia y sonríe, pero la agonía permanece.

El tiempo que destruye es el tiempo que conserva, como el río con su carga de negros muertos, vacas y jaulas vacías, la manzana amarga y la mordida en la manzana.

Y la roca escarpada en las aguas sin descanso

- las olas la bañan, la niebla la cubreen un día de calma es solo un monumento, en tiempo navegable es siempre una marca para fijar el curso; pero en la estación sombría o en la furia repentina, es lo que siempre fue.

\section{III}

A veces me pregunto si esto es lo que Krishna pretendía decir, entre otras cosas, o una manera de expresar lo mismo: que el futuro es un canto desgastado, una rosa real o un ramo de lavanda de ansiosa pena por los que no han llegado aún para penar, prensado entre las hojas amarillas de un libro que nunca ha sido abierto. Y el camino que sube es el mismo que baja, y el camino que avanza, el que regresa.

No puedes enfrentarlo con firmeza, pero una cosa es cierta, que el tiempo no cura: el paciente ya no está aquí.

Cuando parte el tren, y los viajeros se ocupan de frutas, periódicos y cartas de negocios (y aquellos que los vieron partir han dejado el andén) su gesto se relaja del dolor al alivio al ritmo adormilado de cien horas. ¡Sigan adelante, viajeros!, sin huir del pasado rumbo a vidas distintas o hacia algún futuro; no son los mismos que dejaron la estación ni los que llegarán a algún destino, mientras los rieles convergentes se deslizan y se pierden tras ustedes; y en la cubierta del barco que murmura, 
al mirar la estela que a sus espaldas se ensancha no pensarán: "se terminó el pasado" o "el futuro está frente a nosotros". Al caer la noche, entre la antena y los cordajes hay una voz que canta (pero no al oído, murmurante caracol del tiempo, ni en lengua alguna):

"iSigan adelante! Ustedes que creen que viajan, no son aquellos que vieron el puerto alejarse, ni quienes desembarcarán. Entre la orilla próxima y la lejana, mientras el tiempo se retira, consideren el futuro y el pasado con ecuanimidad.

En el instante que no es de acción ni de inacción pueden admitir esto: 'en cualquier esfera del ser la mente del hombre debe estar atenta al momento de la muerte' - esa es la única acción (y el momento de la muerte es todo el tiempo) que dará fruto en la vida de los otros: y no piensen en el fruto de la acción. ¡Sigan adelante!

Oh viajeros, oh marinos,

ustedes que llegan a puerto, y ustedes cuyos cuerpos sufrirán el proceso y juicio de los mares, o cualquier suceso: este es su destino verdadero." Así habló Krishna, como al aconsejar a Arjuna en el campo de batalla.

No adiós, sino sigan adelante, viajeros.

Señora, tú que tienes tu altar sobre el risco ruega por los que se embarcan, por aquellos cuyos negocios tienen que ver con peces, por aquellos que se ocupan de todo comercio legítimo y por aquellos que los conducen. 
Ruega también por las mujeres

que vieron a sus hijos y esposos embarcarse y no volver:

figlia del tuo figlio,

reina del cielo.

Y ruega por los que se embarcaron

y terminaron su viaje en la arena, en los labios del mar,

o en la garganta oscura que no los devolverá

o donde quiera que no los alcancen las campanas del mar, su sonido de Ángelus perpetuo.

\section{V}

Comunicarse con Marte, conversar con espíritus, explicar la conducta del monstruo marino, leer en el horóscopo, las entrañas de las aves o la bola de cristal, diagnosticar enfermedad por medio de la firma, descifrar la biografía en las líneas de la mano y la desgracia en los dedos, hacer presagios por adivinación u hojas de té, desentrañar lo inevitable con la baraja, jugar con símbolos mágicos o con barbitúricos, o buscar la imagen recurrente en los miedos arcaicos, explorar el útero, la tumba o los sueños; son estas las habituales drogas y distracciones, y encabezados de la prensa: y siempre lo serán, algunos sobre todo cuando hay desdicha en las naciones, y perplejidad, sea en las costas de Asia o en Edgware Road. La curiosidad humana busca en el pasado y en el futuro y se aferra a esa dimensión. Pero atrapar el punto en que se cruzan lo intemporal y el tiempo es una tarea para los santos - y tampoco es una tarea, sino algo que se da y se toma, en toda una vida de morir de amor, pasión y desprendimiento y entrega. 
Para casi todos nosotros solo existe el momento desatendido, el momento dentro y fuera del tiempo, el ataque de distracción que se pierde en una franja de sol, el tomillo silvestre que no vemos, o el destello de invierno, o la cascada, o la música tan profundamente escuchada que no se escucha más, pero uno es la música mientras la música dura. Estas son solo pistas y conjeturas, pistas seguidas de conjeturas; y lo demás

es oración, observancia, disciplina, pensamiento y acción.

La pista adivinada a medias, el don a medias comprendido es la Encarnación.

Aquí, la unión imposible

de las esferas de la existencia es real;

aquí, el pasado y el futuro

se superan y reconcilian;

de otro modo, la acción sería solo un movimiento

de aquello que es movido

y no se mueve por sí mismo

—conducido por fuerzas demoniacas y

subterráneas. Y la recta acción también

es libertad ante el pasado y el futuro.

Para casi todos nosotros, esta es la meta

que nunca hemos de alcanzar aquí;

nosotros, solamente invictos

porque hemos seguido intentándolo;

nosotros, satisfechos al fin,

si nuestra reversión en el tiempo alimenta

(no muy lejos del árbol siempre verde)

la vida de la tierra que da sentido. 
CITAM Derechos Reservados.

La reproducción total o parcial de este artículo se podrá hacer si el ITAM otorga la autorización previamente por escrito. 